\title{
HAPTICS AND ITS EFFECT ON CONSUMERS' INTENTIONS USING NEUROSCIENTIFIC METHODS: LITERATURE REVIEW
}

\author{
Jan Vrána ${ }^{1}$, Stanislav Mokrý1 \\ ${ }^{1}$ Department of Marketing and Trade, Faculty of Business and Economics, Mendel University in Brno, \\ Zemědělská 1, 61300 Brno, Czech Republic
}

Link to this article: https://doi.org/10.11118/actaun202068020451

Received: 9. 1.2020, Accepted: 8. 4. 2020

To cite this article: VRÁNA JAN, MOKRÝ STANISLAV. 2020. Haptics and Its Effect on Consumers' Intentions Using Neuroscientific Methods: Literature Review. Acta Universitatis Agriculturae et Silviculturae Mendelianae Brunensis, 68(2): 451-457.

\begin{abstract}
The haptic properties of a product have mostly been underestimated with most studies focusing on visual aspects of objects. Nonetheless, in the last years, it has been found that tactile stimuli are in some cases even more important than the visual ones. However, the traditional paper-based surveys cannot fully and objectively examine their effects on consumers. Therefore, neuroscientific methods, which overcome these obstacles, are becoming more used but there is still only a small number of studies focusing on the effect of haptics in marketing. Using the keywords haptics, tactile input, EEG, fMRI and tactile, seven relevant studies have been found and used in this literature review, out of which four have used EEG and three fMRI. Thus, the main objective of this paper is to review the research that has been already conducted and to identify the areas in which further research should be made and the neuroscientific methods which could be used.
\end{abstract}

Keywords: haptics, tactile, tactile input, electroencephalography (EEG), fMRI

\section{INTRODUCTION}

Our senses are crucial in experiencing and understanding the world we live in. Human cognition is based on information we gain through the sensory channels of sight, hearing, taste, touch and smell (Neisser, 1976). The traditional forms of media such as the Internet or television use the verbal and visual channel to deliver information to viewers. The human consumption, however, is a complicated multisensory process (Hirschman and Holbrook, 1982; Holbrook, 1982, 1983) and is not limited only to these two senses. In order to fully understand all the aspects of product evaluation we need to explore how it is influenced and shaped by all of the senses (Citrin et al., 2003).

Sensory marketing is an emerging research field (Kampfer et al., 2017) which is focused on just that, it is based on the concept that we are more likely to memorize and then retrieve the memory when all the senses are involved (sight, hearing, smell, taste and touch) (Roopchund et al., 2016). The importance and the role of different sensory modalities was examined by Schifferstein (2006), during this study 45 different products were used. Vision was determined to be the most important sense in evaluating a product and it was followed by touch, smell, hearing and taste (Workman, 2009).

The skin, the organ through which we experience touch sensations, is the largest body and sensory organ and the tactile sense (or the sense of touch) is the first sense to develop in infants (Gallace et al., 2010; Atkinson and Braddick, 1982; Miodownik, 2005). From the moment we are born we use our hands to explore the world and acquire information about our surroundings (for example, Piaget 1952; Bushnell and Boudreau, 1991). Adults do this also, but considerably less. The theory is that experiences 
gained through interacting physically with one's surroundings (such as haptic interaction) will later on subconsciously influence actions and opinions in life (Williams and Bargh, 2010). These early sensory experiences form a foundation which is then used for the development of knowledge which can be used at a later point in one's life (Mandler, 1992). Furthermore, the tactile sense is considered to be the most intimate one with the need for physical contact with the skin. This contact can be facilitated by different parts of our bodies; however, the hands play a vital role as an input to the touch perceptual system (Peck and Childers, 2003a) and this process specifically is being called "haptics" (Gibson, 1966).

The vision has been traditionally considered to be the most important sense in product evaluation (for example, Ernst and Banks, 2002; Warren and Rossano, 1991), although it has been known that all kinds of sensory information are being gathered by consumers in order to judge and evaluate a product (Jansson-Boyd, 2011). Vision of course plays an important role in this process, although touch can be as much important as the visual sense (JanssonBoyd, 2011). Despite having this information, touch has scarcely been used as a communication tool, however, as a recent development, marketers are attempting to use tactile stimuli increasingly more. This review attempts to summarize the studies which have been conducted.

\section{Effects of Haptics on Consumer}

Brands can be differentiated from their competitors by the products' haptic properties and customers do often touch the products before making a final decision (Peck and Childers, 2003b). Therefore, if brands want to have a positive impact on a consumer's decision making, customer must be allowed to touch the products (Peck and Wiggins, 2006). As for the cases, in which the haptic properties of a product are important (e.g., a blanket or a jumper), customers prefer to shop for these products in an offline setting, rather than online (McCabe and Nowlis, 2003). For these products tactile input is essential for deciding. Furthermore, objects that are easily grasped are preferred by customers, e.g., a firm cup would provide a better drinking experience than an unstable one. Meaning that the consumer perception of a product can be influenced by its haptic properties (Krishna and Morrin, 2008).

The texture, hardness, temperature and weight of a product are properties that can be explored only through haptic manipulation. These four attributes were named "material properties" (Klatzky and Lederman, 1992, 1993; Klatzky et al., 1993;) and people can obtain a detailed impression of a product and in some cases even more comprehensive information than through different sensory channels by simply touching an object (Peck and Childers, 2003a, 2003b). As a result, customers can be more confident and sure in their decision to purchase
(Citrin et al., 2003), are more likely to impulsively shop (Peck and Childers, 2006) and are more willing to pay (WTP) (e.g., Peck and Shu, 2009; Peck, Barger and Webb, 2013). It has also been discovered that once a consumer's focus is on haptic properties of a product, it is difficult to shift their attention away and it is less likely that they will focus on a product by a competing brand (for example, Spence, Nicholls and Driver, 2001; Spence, Shore and Klein, 2001; Turatto et al., 2004). However, it has been determined that some people are influenced by touch and haptic properties of products more than others (Peck and Childers, 2003a).

On the other hand, when consumers are deprived of touching the products, their decisions are also affected (Peck, 1999; Peck and Childers, 2003b). This is probably caused by touch being a crucial part of product expectations (Schifferstein and Spence, 2008) and these are at least partially formed by previous experiences (Jansson-Boyd and Marlow, 2007). Therefore, if a customer expects to be able to physically hold a product and this expectation is not met, it can lead to frustration, especially if a customer has a need for some sort of tactile information (Peck, 1999; Peck and Childers, 2003b). Such customers tend to have less confidence in their decisions, this is caused by the fact that they cannot use their tactile experiences (Peck, 1999). On the other hand, in environments where tactile input is not a possible option (such as when shopping online), only a verbal description of material properties of a product can compensate for a lack of touch (Peck and Childers, 2003b).

The information gained through tactile input can influence persuasion in different ways. Firstly, products possessing tactile attributes which can be determined only by touch (such as softness of a blanket) are more positively viewed and customers are more likely to purchase them when they are able to touch them (Grohmann, Spangenberg and Sprott, 2007; Peck and Childers, 2003a, 2003b). Furthermore, certain products with the material properties that can be determined only by touch, cannot be successfully sold online due to the inability to fully explore their material properties (Citrin et al., 2003; McCabe and Nowlis, 2003).

Touch can be divided into two forms, one is instrumental, a consumer touches the product to ascertain certain product qualities or characteristics with a typical purchase goal. The other form is a hedonic touch, often with no product purchase goal, the goal is to enjoy the experience itself (Peck, 2009).

\section{Need for Neuroimaging Studies}

Haptic properties of a product can influence consumers' preferences and those can in turn affect purchasing intentions. That is why there is an apparent need for understanding how exactly haptic preference for products is formed (Oliver and Linda, 1981). 
The research focused on this issue has been traditionally conducted via paper-based evaluation methods. This approach has, however, several downsides (Morin, 2011). Firstly, the results are environment dependent (i.e., dependent on the person asking the questions, the way the survey is conducted, etc.). Secondly, the said traditional survey is always conducted post-event (i.e., after particular haptic experience), so there is not an option to investigate the participants' responses in real time during the experience (Ariely and Berns, 2010). Considering that the human memory often exaggerates or is skewed (Loftus and Pickrell, 1995; Hyman and Pentland, 1996) even more so if more time has passed since the haptic experience, these kinds of surveys do not tend to be the most reliable (Morin, 2011). As a solution to these issues, more objective indirect evaluations with the use of neuroimaging methods have been emerging in the last years (e.g., EEG or fMRI) (Wang and Minor, 2008).

\section{MATERIALS AND METHODS}

This literature review of neuroimaging studies is based on articles concerning the effect of haptic properties on purchase intentions and human brain in general. The studies used for this article were collected via metasearch engine EBSCO Discovery Service containing documents available within Mendel University (and also Masaryk University). Initially 54 articles were found using the keywords: haptics, tactile, touch, consumer behavior, decision making, EEG, fMRI. The original articles were then studied and the amount was then reduced to 16 based on their contents. Eventually, after detailed analysis, only 7 of them were used for this review. However other studies are also quoted in other parts of this study because of their general nature.

\section{Literature Review of Neuroimaging Studies}

The field of marketing which uses neuroscientific methods to analyse and understand human behaviour is called neuromarketing. The specific methods applied in neuromarketing research use powerful brain imaging tools gathering information on brain activity (Vecchiato et al., 2011).

There are many studies focused on the tactile properties of objects and their effect on human brain. However, only a small amount of these studies is dealing with haptics in context of marketing. A vast majority of studies are designed to explore the brain areas which deal with haptics in general or the difference between pleasant touch, neutral touch and painful touch.

This literature review focuses primarily on the marketing-oriented experiments, i.e., how material properties of a product can influence product evaluation or purchase intention. As that may be, the non-marketing-oriented studies are mentioned also, as they may obtain important findings which are needed in order to fully understand how haptics can be used in marketing.

The studies included in this literature review use primarily functional Magnetic Resonance Imaging (fMRI) and electroencephalogram (EEG). The information gathered with the use of these neuroscientific methods are generally more objective and reliable than those collected via traditional paper-based surveys, largely because

I: Comprehensive summary of haptic research on the usage of neuroimaging tools

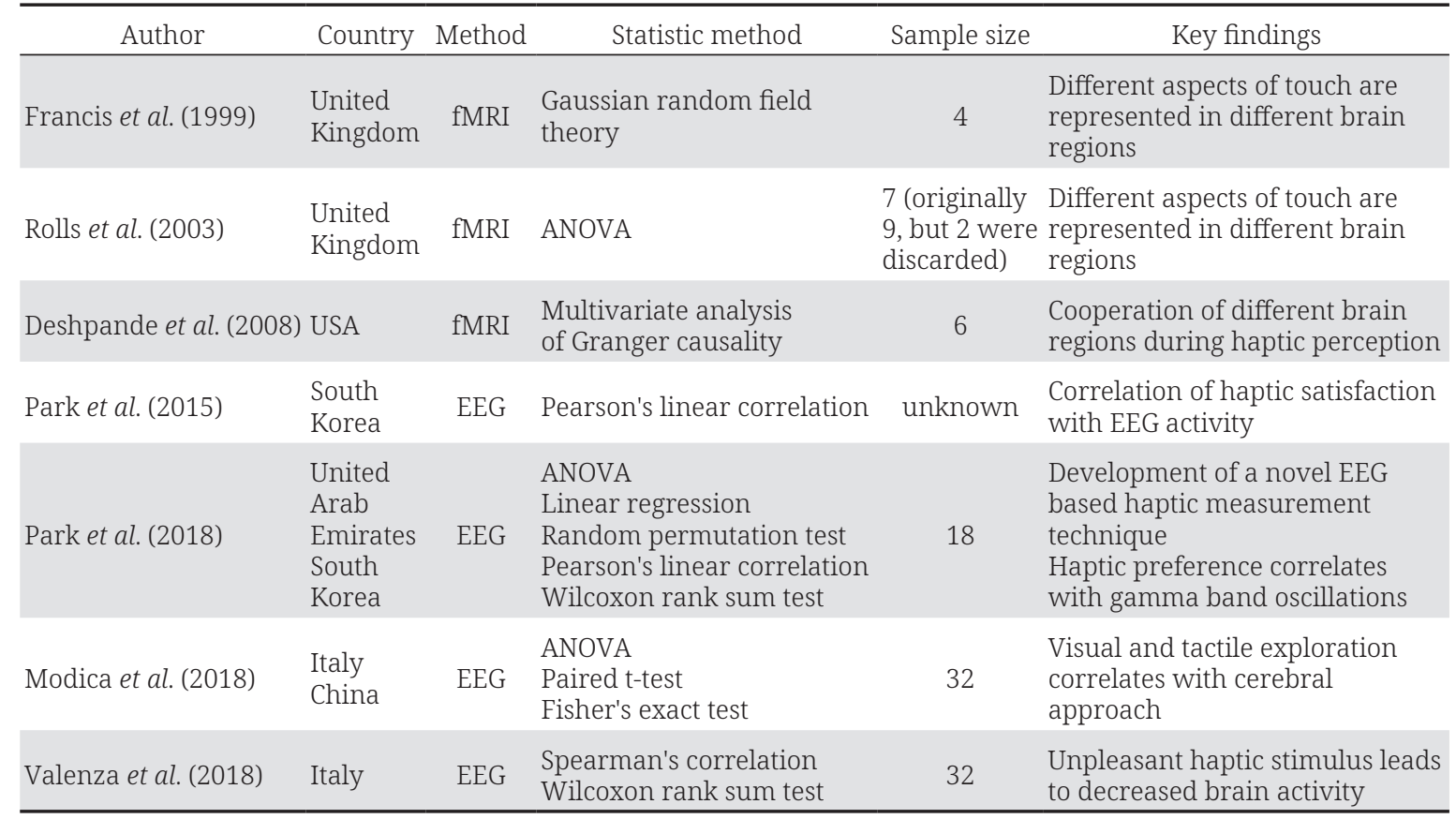

Source: authors' results 
these surveys are conducted post-event and human memory often distorts reality (Ariely and Berns, 2010). Furthermore, human emotions and intentions are difficult to explain to other persons, resulting in these methods becoming more frequent in marketing research (Vecchiato et al., 2011).

Tab. I summarises the studies used in this review, their important characteristics and key findings. Only studies using neuroscientific methods such as EEG and fMRI were included, as this review focuses mainly on the use of these neuroscientific methods in investigating haptics, it's representation in the brain and the use of haptic properties in marketing. The table includes information on the authors; the country, where the studies originated; the type of scientific method the study used (EEG or fMRI) and the statistical methods used. Furthermore, the number of participants and key findings are also included.

\section{Studies Using EEG}

Most of the selected studies used EEG as a method of recording neural responses. The main advantage of this non invasive method lies in the possibility to record neural responses while the participants are interacting with the product, therefore there is no delay between the experience itself and the response recording as it is with traditional surveys (Park et al., 2018).

The material (or haptic) properties of a product such as texture, softness, temperature and weight are often as important as the visual profile of a product. If consumers develop strong haptic preference toward a product, the likelihood of the purchase is higher (Park et al., 2018). Therefore, understanding the overall process of receiving haptic input and its effect on consumers is crucial in order to fully explore the possibilities in marketing.

Two of the studies included investigated correlation between haptic properties of a product and consumer preference and satisfaction (Park et al., 2018, 2015). Both focused on the haptic interface of a dial knob of a commercial washing machine. During the manipulation of the knob, EEG signals were recorded. The results of these two studies revealed significant correlation between the level of haptic preferences and the gamma oscillations. The higher the haptic preference was, the stronger were the gamma oscillations. Both studies also revealed that in the early period of the task (turning the knob) was the correlation highest. This means that the haptic properties of a product influence our preferences most in the beginning of the interaction (Park et al., 2018, 2015).

The remaining two studies focused on different kinds of haptic interaction. The first one examined how is evaluation of a food product influenced by its sensory properties (visual and tactile) (Modica et al., 2018). The results showed significantly higher EEG activity during visual and tactile exploration phases. This study also focused on the difference between the comfort food and daily food groups, major and private brands and foreign and local brands. Higher cognitive and emotional activity was recorded when participants were freely handling and touching comfort and foreign foods (Modica et al., 2018).

The last study using EEG examined oscillations during caress-like touches. Participants were examined when being caressed on their forearms. A correlation was discovered between the oscillations and caressing force. The more unpleasant the stimulus on the skin is, the more the brain activity decreases all over the head (Valenza et al., 2018).

\section{Studies Using fMRI}

The studies employing fMRI as a scientific method were focused more on different brain regions involved in tactile interactions with different products. The first two studies examined what regions of brain are activated by pleasant and painful touch (Rolls et al., 2003). There have been many studies focusing on representation of pain in the human brain, whereas pleasant touch has not been investigated often. These two experiments show that different kinds of touch (a pleasant, neutral and a painful one) is represented in different brain regions. Furthermore, the aspect causing these differences is not the intensity, however, it is the pleasantness of the touch (Francis et al., 1999). These finding are important in understanding how human emotions work and how they can be affected (Francis et al., 1999).

The third fMRI study focused on perceived separation of brain regions. During haptic interaction with products, fMRI data were recorded, and areas generally considered to work separately were found to cooperate with different brain regions in a process called "effective connectivity" (Deshpande et al., 2008).

\section{CONCLUSION}

This review's aim was to review the research that has been made on the topic of neuroscientific methods used in examination of tactile input and its effect on the consumers' behavior. The review shows that research into haptics in general and the use of haptics in marketing is a valuable and perhaps underestimated field. In investigating interaction with products, the focus has mostly been on the visual properties of objects. In the last years however, the focus has been on haptic properties increasingly more as it has been found that the haptic properties of a product are in some cases even more important than the visual aspects. However, the research of the effect of tactile stimuli 
on consumers via traditional paper-based surveys have been proven to be difficult and that is why neuroscientific methods are used increasingly more. The importance of haptics in marketing has, however, not been fully examined yet and there is only a small amount of experiments using neuroscientific methods, many of them have been included in this literature review. The reasons as to why there are not more studies using these methods are multiple; the purchase price of the machines needed is much higher than with traditional paper-based surveys and the logistics of such research are also more complicated (especially with fMRI). However, there are other neuroscientific methods, which are perhaps more accessible with lower purchase costs (e.g. Functional near infrared spectroscopy or Magnetoencephalography. Also, the Facial Expression Analysis could be utilized in examination of emotion expressed while manipulating and object). To summarize, there are many methods with lower price point which can be utilized in this research field. Another aim of this article was to highlight the areas with potential for further research and these methods could be used for fulfilling this potential.

\section{Acknowledgements}

This paper is the result of a research project supported by the Faculty of Business and Economics, MENDELU, No. PEF_TP_2019007 "Sensory Marketing: Haptics and its Importance in Consumer Decision Making”.

This paper was supported by the project CZ.02.1.01/0.0/0.0/16_017/0002334 Research Infrastructure for Young Scientists, co-financed by Operational Programme Research, Development and Education.

\section{REFERENCES}

ARIELY, D. and BERNS, G. S. 2010. Neuromarketing: The hope and hype of neuroimaging in business. Nature Rev. Neurosci., 11(4): 284-292.

ATKINSON, J. and BRADDICK, O. 1982. Sensory and perceptual capacities of the neonate. In: STRATTON, P. (Ed.). Psychobiology of the human newborn. London: John Wiley, pp. 191-220.

BUSHNELL, E. W. and BOUDREAU, J. P. 1991. The development of haptic perception during infancy. In: HELLER, M. A. and SCHRIFF, W. (Eds.). The psychology of touch. New Jersey: Lawrence Erlbaum Associates, pp. 139-161.

CITRIN, A. V., STERN, D. E., SPANGENBERG, E. R. and CLARK, M. J. 2003. Consumer need for tactile input: An Internet retailing challenge. Journal of Business Research, 56(11): 915-922.

DESHPANDE, G., HU, X., STILLA, R. and SATHIAN, K. 2008. Effective connectivity during haptic perception: A study using Granger causality analysis of functional magnetic resonance imaging data. NeuroImage, 40(4): 1807-1814.

ERNST, M. O. and BANKS, M. S. 2002. Humans integrate visual and haptic information in a statistically optimal fashion. Nature, 415: 429-433.

FRANCIS, S., ROLLS, E. T., BOWTELL, R., MCGLONE, F., O'DOHERTY, J., BROWNING, A., CLARE, S. and SMITH, E. 1999. The representation of pleasant touch in the brain and its relationship with taste and olfactory areas. Neuroreport, 10(3): 453-459.

GALLACE, A., ZEEDEN, S., RÖDER, B. and SPENCE, C. 2010. Lost in the move? Secondary task performance impairs tactile change detection on the body. Consciousness and Cognition, 19(1): 215229.

GIBSON, J. J. 1966. The senses considered as perceptual systems. Boston: Houghton Mifflin.

GROHMANN, B., SPANGENBERG, E. R. and SPROTT, D. E. 2007. The influence of tactile input on the evaluation of retail product offerings. Journal of Retailing, 83(2): 237-246.

HOLBROOK, M. B. 1982. Some future dimensions of psycholinguistics, imagery, and consumer response. In: MITCHELL, A. A. (Ed.). Advances in consumer research. Vol. 9. Ann Arbor, MI: Association for Consumer Research, pp. 112-117.

HOLBROOK, M. B. 1983. Product imagery and the illusion of reality: some insights from consumer esthetics. In: TYBOUT, A. and BAGOZZI, R. (Ed.). Advances in consumer research. Vol. 10. Ann Arbor, MI: Association for Consumer Research, pp. 65-71.

HIRSCHMAN, E. and HOLBROOK, M. B. 1982. Hedonic consumption: emerging concepts, methods and propositions. J. Mark., 46(3): 92-101.

HYMAN, I. E., JR. and PENTLAND, J. 1996. The role of mental imagery in the creation of false childhood memories. J. Memory Lang., 35(2): 101-117.

JANSSON-BOYD, C. V. 2011. Touch matters: exploring the relationship between consumption and tactile interaction. Social Semiotics, 21(4): 531-546. 
JANSSON-BOYD, C. V. and MARLOW, N. 2007. Not only in the eye of the beholder: Tactile information can affect aesthetic evaluation. Psychology of Aesthetics, Creativity and the Arts, 1(3): 170-173.

KAMPFER, K., LEISCHNIG, A., IVENS, B. S., SPENCE, C. and BRUCE, A. 2017. Touch-flavor transference: Assessing the effect of packaging weight on gustatory evaluations, desire for food and beverages, and willingness to pay. Plos One, 12(10): e0186121.

KLATZKY, R. L. and LEDERMAN, S. J. 1992. Stages of manual exploration in haptic object identification. Perception and Psychophysics, 52(6): 661-670.

KLATZKY, R. L. and LEDERMAN, S. J. 1993. Toward a computational model of constraint driven exploration and haptic object identification. Perception, 22(5): 597-621.

KLATZKY, R. L., LEDERMAN, S. J. and MATULA, D. E. 1993. Haptic exploration in the presence of vision. Journal of Experimental Psychology: Human Perception and Performance, 19(4): 726-743.

KRISHNA, A. and MORRIN, M. 2008. Does touch affect taste? The Perceptual transfer of product container haptic cues. Journal of Consumer Research, 34(6): 807-818.

LOFTUS, E. F. and PICKRELL, J. E. 1995. The formation of false memories. Psychiatric Ann., 25(12): 720-725.

MANDLER, J. M. 1992. How to build a baby. II. Conceptual primitives. Psychological Review, 99(4): 587-604.

MCCABE, D. and NOWLIS, S. 2003. The effect of examining actual products or product descriptions on consumer preference. Journal of Consumer Psychology, 13(4): 431-439.

MIODOWNIK, M. 2005. A touchy subject. Materials today, 8(6): 6-6.

MODICA, E., CARTOCCI, G., ROSSI, D. et al. 2018. Neurophysiological Responses to Different Product Experiences. Computational Intelligence and Neuroscience, Special Issue: 9616301.

MORIN, C. 2011. Neuromarketing: the new science of consumer behavior. Society, 48: 131-135.

NEISSER, U. 1976. Cognition and reality: principles and implications of cognitive psychology. San Francisco: Freeman.

OLIVER, R. L. and LINDA, G. 1981. Effect of satisfaction and its antecedents on consumer preference and intention. Adv. Consum. Res., 8: 88-93.

PARK, W., KI, D., KIM, D.-H., KWON, G. H., KIM, S.-P. and KIM, L. 2015. EEG correlates of user satisfaction of haptic sensation. In: 2015 IEEE International Conference on Consumer Electronics (ICCE). IEEE, pp. 569-570.

PARK, W., KIM, D.-H. KIM, S.-P., LEE, J.-H. and KIM, L. 2018. Gamma EEG Correlates of Haptic Preferences for a Dial Interface. IEEE Access, 6: 22324-22331.

PECK, J. 1999. Extraction of Haptic Properties: Individual Characteristics and Stimulus Characteristics. Doctoral Dissertation. Department of Marketing, University of Minnesota.

PECK, J. and CHILDERS, T. L. 2003a. Individual differences in haptic information processing: The "need for touch" scale. The Journal of Consumer Research, 30(3): 430-442.

PECK, J. and CHILDERS, T. L. 2003b. To have and to hold: The influence of haptic information on product judgments. Journal of Marketing, 67(2): 35-48.

PECK, J. and CHILDERS, T. L. 2006. If I Touch It I Have to Have It: Individual and Environmental Influences on Impulse Purchasing. Journal of Business Research, 59(6): 765-769.

PECK, J. and WIGGINS, J. 2006. It just feels good: Customers' affective response to touch and its influence on persuasion. Journal of Marketing, 70(4): 56-69.

PECK, J. 2009. Does touch matter? Insights from haptic research in marketing. In: KRISHNA, A. (Ed.). Sensory marketing: A confluence of psychology, neuroscience and consumer behavior research. New York: Psychology Press/Routledge.

PECK, J. and SHU, S. B. 2009. The Effect of Mere Touch on Perceived Ownership. Journal of Consumer Research, 36(3): 434-447.

PECK, J., BARGER, V. A. and WEBB, A. 2013. In Search of a Surrogate for Touch: The Effect of Haptic Imagery on Perceived Ownership. Journal of Consumer Psychology, 23(2): 189-196.

PIAGET, J. 1952. The origins of intelligence in children. New York: International University Press.

ROLLS, E. T., O'DOHERTY, J., KRINGELBACH, M. I., FRANCIS, S., BOWTELL, R. and MCGLONE, F. 2003. Representations of pleasant and painful touch in the human orbitofrontal cingulated cortices. Cerebral Cortex, 13(3): 308-317.

ROOPCHUND, R., KHIRODHUR, L., PANYANDEE, T. and BAPPOO, M. 2016. Analyzing the Impact of Sensory Marketing on Consumers: A Case Study of KFC. Journal of US-China Public Administration, 13(4): 278-292.

SCHIFFERSTEIN, H. N. J. 2006. The perceived importance of sensory modalities in product usage: A study of self-reports. Acta Psychologica, 121(1): 41-64.

SCHIFFERSTEIN, H. N. J. and SPENCE, C. 2008. Multisensory product experience. In: SCHIFFERSTEIN, H. N. J. and HEKKERT, P. (Eds.). Product experience. Amsterdam: Elsevier, pp. 133-161. 
SPENCE, C., NICHOLLS, M. E. R. and DRIVER, J. 2001. The cost of expecting events in the wrong sensory modality. Perception and Psychophysics, 63(2): 330-333.

SPENCE, C., SHORE, D. I. and KLEIN, R. M. 2001. Multimodal prior entry. Journal of Experimental Psychology: General, 130: 799-832.

TURATTO, M., GALFANO, G., BRIDGEMAN, B. and UMILTA, C. 2004. Space-independent modality driven attentional capture in auditory, tactile and visual systems. Experimental Brain Research, 155(3): 301-310.

VALENZA, G., GRECO, A., BIANCHI, M., NARDELli, M., ROSSI, S. and SCILINGO, E. P. 2018. EEG oscillations during caress-like affective haptic elicitation. Psychophysiology, 55(10): e13199.

VECCHIATO, G., ASTOLFI, L., DE VICO FALLANI, F. et al. 2011. On the Use of EEG or MEG Brain Imaging Tools in Neuromarketing Research. Computational Intelligence and Neuroscience, 2011(1687-5265): 643489

WANG, Y. J. and MINOR, M. S. 2008. Validity, reliability, and applicability of psychophysiological techniques in marketing research. Psychology \& Marketing, 25(2): 197-232.

WARREN, D. H. and ROSSAN, M. J. 1991. Intermodality relations vision and touch. In: HELLER, M. A. and SCHIFF, W. (Eds.). The psychology of touch. Hillsdale, NJ: Erlbaum, pp. 119-137.

WILLIAMS, L. E. and BARGH, J. A. 2008. Experiencing physical warmth promotes interpersonal warmth. Science, 322(5901): 606-607.

WORKMAN, J. E. 2009. Fashion Consumer Groups, Gender, and Need for Touch. Clothing and Textiles Research Journal, 28(2): 126-139.

Jan Vrána: xvrana4@mendelu.cz Stanislav Mokrý: stanislav.mokry@mendelu.cz 